\title{
Esophageal Granular Cell Tumor and Eosinophilic Esophagitis: Two Interesting Entities Identified in the Same Patient
}

\author{
Alfredo J. Lucendo ${ }^{\mathrm{a}}$ Livia De Rezende ${ }^{\mathrm{a}}$ \\ Jesús Martín-Plaza ${ }^{a}$ Javier Larraurib \\ Departments of a Gastroenterology and ${ }^{b}$ Pathology, Hospital Universitario La Paz, \\ Madrid, Spain
}

\section{Key Words}

Eosinophilic esophagitis · Granular cell tumors · Dysphagia · Esophagus

\begin{abstract}
We illustrate the case of a 41-year-old male with allergic manifestations since childhood. He sought medical attention for intermittent, progressive dysphagia from which he had been suffering for a number of years, having felt the sensation of a retrosternal lump and a self-limited obstruction to the passage of food. Endoscopy detected a submucosal tumor in the upper third of the esophagus, which was typified, via biopsy, as a granular cell tumor with benign characteristics and probably responsible for the symptoms. Two years later, the patient sought medical attention once again as these symptoms had not abated, hence digestive endoscopy was repeated. This revealed stenosis of the junction between the middle and lower thirds of the organ which had not been detected previously but was passable under gentle pressure. Eosinophilic esophagitis was detected after biopsies were taken. Esophageal manometry identified a motor disorder affecting the esophageal body. Following three months of treatment using fluticasone propionate applied topically, the symptoms went into remission, esophageal stenosis disappeared and the esophageal biopsies returned to normal. This is the first documented case of the link between granular cell tumors and Eosinophilic esophagitis, two different disorders which could cause dysphagia in young patients.
\end{abstract}




\section{Introduction}

Granular cell tumors were first described as myoblastoma by Abrikossof in 1926 [1]. This tumor is rare, usually benign and of neuroectodermic origin in the Schwann cells [2]. It has been described at multiple locations and is the second greatest cause of esophagheal mesenchymal tumors, after leiomyoma. Eosinophilic esophagitis (EE) is a clinicopathological entity which is allergic in origin and was characterised by Attwood in 1993 [3]. Both processes can cause dysphagia via different mechanisms. This is the first documented case of a patient suffering from both entities, who was diagnosed via digestive endoscopy and biopsy.

\section{Case Report}

A 41-year-old male with a history of allergic asthma since childhood, rhinoconjunctivitis and sensitivity to pollen, attended the gastroenterology clinic having suffered from progressive dysphagia on an infrequent basis over a number of years. The patient described symptoms of a retrosternal lump, and felt as if something were blocking the passage of food in his esophagus. These episodes varied in length and subsided of their own accord after several minutes without requiring endoscopic intervention. The symptoms had recurred on a number of occasions and were not linked to any specific food type. He showed no signs of nausea, regurgitation, pyrosis, abdominal pain or weight loss.

After an endoscopy was carried out, a tumor was detected in the upper third of the organ which was submucosal, yellowish in color, molar-shaped and hard to the touch using the biopsy tweezers. It measured approximately $5 \mathrm{~mm}$, did not restrict the passage of the endoscope and was coated in normal mucosa (fig. 1). The biopsies showed that the submucosal esophageal stroma were infiltrated by nests of cells with ample, granular eosinophilic cytoplasms with central nuclei and showed no indication of atypia or mitosis, in line with esophageal granular cell tumor (fig. 2). The patient had similar symptoms to those related to this type of lesion, and because the tumor was small and the histology showed no indication of malignity, we decided to carry out endoscopic and histological monitoring.

Two years later, the patient was still being attended for episodic dysphagia. During the endoscopic review, performed at that time, the submucosal tumor was once again detected in the upper third, showing no changes. Regular stenosis was also identified in the junction between the upper and middle esophageal thirds which had gone undetected during the previous exploration and was passable under gentle endoscopic pressure. The mucosa of the middle and distal esophagus appeared edematous with a loss of normal vascular pattern and had various longitudinal striae along the folds. The biopsies taken from this area showed epithelial edema, acanthosis and papillomatosis, with dense eosinophilic leucocyte infiltration, by more than 24 eosinophils per high-power field, findings compatible with EE (fig. 3). Biopsies were also taken of the tumor in the upper third which still seemed to be benign. The rest of the stomach and duodenum exploration was normal and the biopsies taken from the antral mucosa did not show any alterations.

The patient was subjected to an ambulatory 24-hour pH-metry, which ruled out pathological gastroesophageal reflux as a possible cause of eosinophilic infiltration of the esophagus, and a stationary esophageal manometry was also performed with the following results: upper esophageal sphincter with normal pressure and pharyngeal coordination, normal pressure and complete relaxation of the lower sphincter. The esophageal body had $20 \%$ non-transmitted waves in the $3 / 3,10 \%$ non-transmitted waves in the upper $2 / 3$ with normal amplitude in the distal third and $70 \%$ peristaltic waves of normal duration with increased amplitude in the distal third.

Upon diagnosis of EE, treatment of topical fluticasone propionate was administered, applied on the tongue using an inhaler device and then swallowed, at a dosage of $500 \mu \mathrm{g}$ every $12 \mathrm{~h}$. The patient was recommended not to eat and drink for several hours after the application of treatment and to rinse out his mouth with water and bicarbonate of soda $20 \mathrm{~min}$ after taking the medication. He was subsequently referred to the allergy clinic to be examined for possible sensitivity to food or airborne allergens.

After three months of treatment, the patient showed substantial clinical improvement and the episodes of dysphagia had subsided. The esophageal mucosa had returned to normal (except for the tumor in the upper third) and the mucosal biopsies showed resolution of the eosinophilic infiltrate and of the histological changes. The manometry which was repeated following treatment showed 
normalisation of the motor function of the esophagus, with $100 \%$ peristaltic waves of normal duration and amplitude in the three thirds.

\section{Discussion}

Endoscopic exploration is a basic technique in the study of dysphagia. In young patients, it is mainly caused by benign disorders associated with acid reflux exposure, leading to very rare malignant neoplasias. In recent years, we have witnessed a considerable rise in the number of reported cases of EE [4], to the extent that this emerging entity should also be included in the differential diagnosis of dysphagia, especially in young patients with a background of allergies [5]. Granular cell tumor or Abrikossoff's tumor is a rare lesion deriving from the Schwann cells of the submucosal plexus neurons of the esophagus of which less than 300 cases have been documented. Most reported cases have involved single lesions located in the distal third, mainly affecting women in their fifties [6], characteristics which were not met by our patient. Although this pathology is usually benign, a few exceptional cases of malignant tumors have been reported, with distant ganglionary metastasis, and these required obligatory histological analysis to rule out this possibility. Certain instances of granular cell tumors synchronically or metachronically linked to malignant neoplasias of the esophagus have also been documented, such as adenocarcinomas or squamous carcinomas [7-9], although the actual extent of this association is unknown.

To date, no cases of granular cell tumors linked to EE have been reported, meaning that our case is the first. Nevertheless, because both disorders suffered by the patient are unrelated in origin (mucosal hypersensitivity and tumoral proliferation of Schwann cells), we believe that association is coincidental.

Given that most esophageal granular cell tumors are small $(<1 \mathrm{~cm})$, diagnosis tends to occur accidentally during endoscopic exploration carried out for another purpose. From the start, our patient's symptoms definitely matched those of EE, but because information on this entity has only recently become available and endoscopic findings are often not very obvious, going undetected by the non-expert, it is likely that the patient's initial diagnosis was incorrect.

EE can be associated with a wide range of endoscopic patterns, including concentric, focal or segmentary stenosis, simultaneous contractions, rings along the organ or subtle findings described regarding the mucosal appearance. A recent review has established that the most common endoscopic findings described in the literature linked to EE were white stipple-like exudates, linear fissures and reddening, but mucosa was regarded as normal in near a quarter of patients [10]. The extensive polymorphism on the endoscopic findings characterizing EE was classified in a recent work according to a manometric and histopathological relationship [11]: Alterations in the esophageal calibre can be related with motor disturbances affecting the two distal thirds of the organ, while varying degrees of intensity in histological damage induced by activation and degranulation of eosinophilic leukocytes lead to different endoscopic patterns, which could be classified in 4 well-defined categories: granular, corrugated, undulated and exudative.

As regards treatment alternatives for EE, both dietetic and pharmacological measures have proven efficient. Children following basic diets (lacking in antigenic capacity) over an 8-week period showed improved symptoms in addition to histological normalisation [12]. Because this measure is difficult to apply to adults, we decided to opt for pharmacological treatment for our patient. Among these options, systemic action 
glucocorticoids $[13,14]$ proved to be efficient given clinical, endoscopic and histologicaltype parameters, although they have potential side effects. Topical corticoids such as fluticasone propionate administered by inhaler are effective and, compared to systemic corticoids, do not have any side effects and are widely used to treat EE in children [15-19] and adults $[20,21]$. Although some reports discuss the use of sodium cromoglycate and antileukotrienes $[22,23]$ in the treatment of EE, these cases are isolated due to limited experience. After 3 months of treatment with fluticasone propionate, we noticed considerable improvement in symptoms such as remission of dysphagia, less time required in having lunch and dinner, as well as resolution of the esophageal inflammatory infiltrate and normalisation of epithelial histological changes. Manometric alterations of the esophagus reverted following treatment, as proof of their functional nature.

Possible therapeutic alternatives for granular cell tumors include endoscopic resectioning of the lesion using a variety of procedures [6], surgical resectioning and an expectant or conservative approach [24] to endoscopic and biopsy monitoring every 6 to 12 months. The latter attitude is the most frequently adopted in literature and is that which is currently recommended for lesions which are generally benign and where malignisation is rare. Provided that the tumor fulfils certain benign criteria, in that it is small $(<10 \mathrm{~mm})$, asymptomatic, does not have a histology of mitosis or dysplasia or changes in size, periodic monitoring can be employed, as this is the safest option with the best cost/efficiency relationship. Considering these characteristics, we adopted a conservative approach towards the Abrikossoff's tumor identified in our patient.

To conclude, this is the first documented case of the link between granular cell tumors and EE. Although both entities are lesions of a different nature and physiopathological origin, they are both interesting pathologies that should be considered during the endoscopic examination of dysphagia in young patients.

Fig. 1. Endoscopic image of our case, which shows a millimetric and yellowish 'molar-like' nodule located in the upper esophagus, impressed into the submucosa.

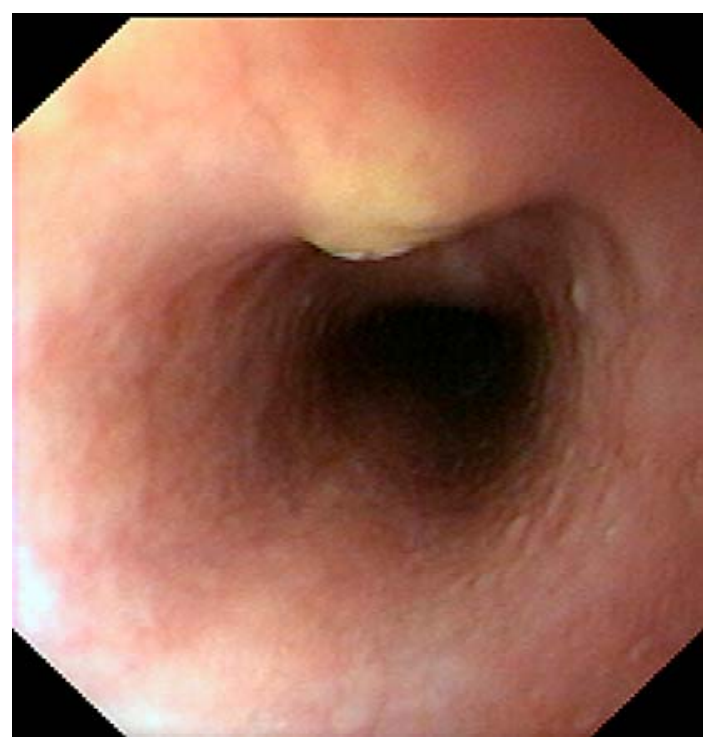




\begin{tabular}{c|l|l|l}
$\begin{array}{r}\text { Case Reports in } \\
\text { Gastroenterology }\end{array}$ & $\begin{array}{l}\text { Case Rep Gastroenterol 2008;2:33-39 } \\
\text { D0I: 10.1159/000113220 }\end{array}$ & Published online: February 5, 2008 & $\begin{array}{l}\text { O 2008 S. Karger AG, Basel } \\
\text { ISSN 1662-0631 } \\
\text { www.karger.com/crg }\end{array}$ \\
\hline
\end{tabular}

Fig. 2. Tissue preparation within which tumor proliferation nests or cords may be observed, immediately below the esophageal epithelium showing signs of hyperplasia with acanthosis and papillomatosis (HE 200×).

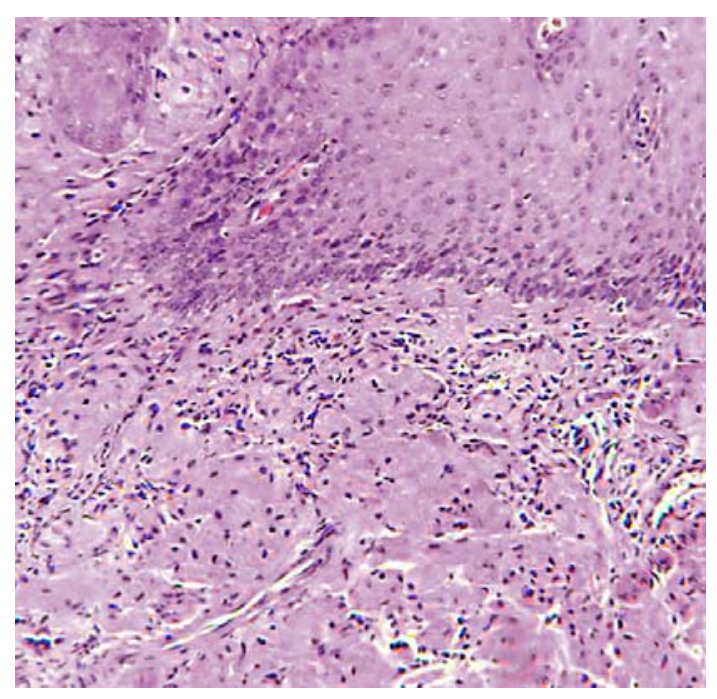

Fig. 3. Biopsy taken over the distal esophageal third, showing regenerative changes expressed like hyperplasia of basal cells and acanthosis, into epithelium containing intercellular edema and eosinophilic infiltration (HE 200×).

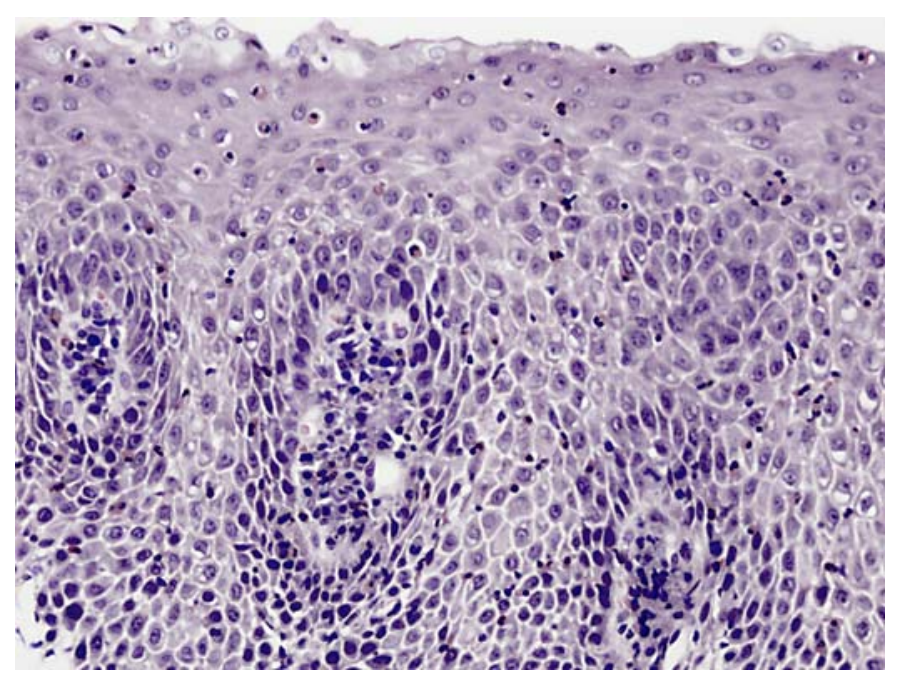




\section{References}

1 Abrikossoff A: Über Myome ausgehend von der quergestreiften willkürlichen Muskulatur. Virchows Arch A Pathol Anat 1929;260:215-233.

2 Levin KJ: Tumors of the esophagus and stomach; in Atlas of Tumor Pathology. AFIP 3 Ed. Fasc 18. Washington, 1996, pp 154-155.

-3 Attwood SE, Smyrk TC, Demeester TR, Jones JB: Esophageal eosinophilia with dysphagia. A distinct clinicopathologic syndrome. Dig Dis Sci 1993;38:109-116.

4 Straumann A, Simon HU: Eosinophilc esopahagitis: escalating epidemiology? J Allergy Clin Immunol 2005;115:418-419.

-5 Lucendo Villarín AJ, Carrión Alonso G, Navarro Sánchez M, Martín Chávarri S, Gómez Senent S, Castillo Grau P, et al: Eosinophilic eosinophilic in adults, an emerging cause of dysphagia. Description of 9 cases. Rev Esp Enf Dig 2005;97:229-239.

-6 De Rezende L, Lucendo AJ, Alvarez-Argüellez H: Granular cell tumors of the esophagus. Report of 5 cases and review of diagnostic and therapeutic techniques. Dis Esophagus 2007;20:436-443.

7 Szumilo J, Danbrowski A, Skomra D, Chibowski D: Coexistence of esophageal granular cell tumor and squamous cell carcinoma: A case report. Dis Esophagus 2002;15:88-92.

8 Vinco A, Vettoreto N, Cervi E, Villanacci V, Baronchelli C, Giulini SM, et al: Association of granular cell tumor and squamous carcinoma of the esophagus: Case report and review of literature. Dis Esophagus 2001;14:262-264.

-9 Joshi A, Chadrasoma P, Kiyabu M: Multiple granular cell tumors of the gastrointestinal tract with subsequent development of esophageal squamous carcinoma. Dig Dis Sci 1992;37:1612-1618.

10 Müller S, Pühl S, Vieth M, Stolte M: Analysis of symptoms and endoscopic findings in 117 patients with histological diagnoses of esinophilic esophagitis. Endoscopy 2007;39:339-344.

- 11 Lucendo AJ, Pascual-Turrión JM, Navarro M, Comas C, Castillo P, Letrán A, et al: Endoscopic, bioptic and manometric findings in eosinophilic esophagitis before and after steroid therapy: A case series. Endoscopy 2007;39:765-771.

12 Kelly KJ, Lazenby AJ, Rowe PC, Yardley JH, Perman JA, Sampson HA: Eosinophilic esophagitis attributed to gastroesophageal reflux: improvement with an amino acid-based formula. Gastroenterology 1995;109:1503-1512.

-13 Borda F, Jiménez FJ, Martínez Peñuela JM, Echarri A, Martín Granizo I, Aznarez R: Esofagitis eosinofílica: ¿una entidad infradiagnosticada? Rev Esp Enf Dig 1996;88:701-704.

14 Liacouras CA, Wenner WJ, Brown K, Ruchelli E: Primary eosinophilic esophagitis in children: successful tratment with oral corticosteroids. J Pediatr Gastroenterol Nutr 1998;26:380-385.

-15 Teitelbaum J, Fox V, Twarog F, Nurko S, Antonioli D, Badizadegan K, et al: Eosinophilic esophagitis in children: Immunopathological analysis and response to fluticasone propionate. Gastroenterology 2002;122:1216-1225.

- 16 Noel RJ, Putman PE, Collins MH, Assa'ad AH, Guajardo JR, Jameson SC, et al: Clinical and immunopathologic effects of swallowed fluticasone for eosinophilic esophagitis. Clin Gastroenterol Hepatol 2004;2:568-575.

17 Faubion WA, Perrault J, Burgart LJ, Zein NN, Clawson M, Furuta GT: Treatment of eosinophilic esophagitis with inhaled corticosteroids. J Pediatr Gastroenterol Nutr 1998;27:90-93.

18 Arora AS, Perrault J, Smyrk TC: Topical corticosteroid treatment of dysphagia due to eosinophilic esophagitis. Mayo Clin Proc 2003;78:830-835.

19 Langdon DE: Fluticasone in eosinophilic corrugated ringed esophagus. Am J Gastroenterol 2001;96:926-927.

20 Remedios M, Campbell C, Jones DM, Kerlin P: Eosinophilic esophagitis in adults: clinical, endoscopic, histologic findings, and response to treatment with fluticasone propionate. Gastrointest Endosc 2006;63:3-12.

21 Perrault J, Arora AS, Clawson ML, Smyrk TC: Treatment of eosinophilic esophagitis with steroid lavage in adult patients (abstract). Am J Gastroenterol 2001;96:S31. 
22 Neustrom MR, Friesen C: Treatment of eosinophilic gastroenteritis with montelukast. J Allergy Clin Immunol 1999;104:506.

23 Attwood SE, Lewis CJ, Bronder CS, Morris CD, Armstrong GR, Whittam J: Eosinophilic esophagitis: A novel treatment using Montelukast. Gut 2003;52:181185.

24 Orlowska J, Pachlewski J, Gugulski A, Butruk E: A conservative approach to granular cell tumor of the esophagus: Four case reports and literature review. Am J Gastroenterol 1993;88:311-314. 